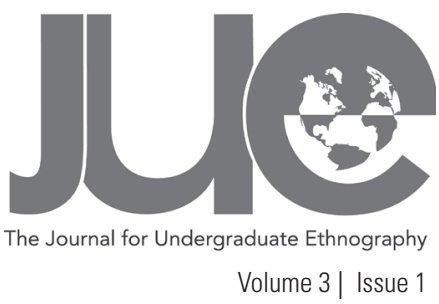

\title{
More Then Just Shelves: Patron Perceptions of a Downtown Halifax Library
}

\author{
Emily Macrae, Stephanie Van de Vooren, Siobhan Witherbee \\ Dalhousie University, eamacrae@gmail.com, steph.vdv@dal.ca, switherbee@dal.ca
}

\section{ABSTRACT}

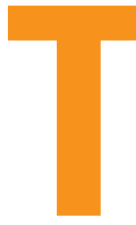

his paper explores how patrons conceive of the Spring Garden Road Memorial Library (SGL) in Halifax, Nova Scotia. Built in 1951 to commemorate local residents who died in the world wars, the SGL will be replaced by the Halifax Central Library by the end of 2014. Our study combines on-site observation and interviews with library patrons to determine how users' behavior at the SGL relates to their opinions of the current building, and the future Halifax Central Library. Although policy documents highlight the shortcomings of the SGL building, many patrons value the SGL because of its connection to local history, as well as its place in their everyday lives.

The contrast between physical conditions and individual perceptions demonstrates the interplay between tangible and intangible factors in shaping urban space.

Keywords: Halifax, Library, Public Space, Social Construction, Social Production 
The Spring Garden Road Memorial Library (SGL) is the oldest and largest branch in the network of Halifax Public Libraries. Centrally located next to a popular public park, the library also occupies a prominent position in the city's downtown core. Built as a living memorial to local residents who died in the world wars, the SGL is caught between its commemorative origins and the contemporary needs of its users. The SGL is of particular interest not only because it is a historidally significant institution that serves a diverse population, but also because the Halifax Central Library, proposed for completion by the end of 2014, will replace the Spring Garden Road branch. Research into the existing library is important because attitudes towards the SGL influence both the planning process and the public reception of the new Halifax Central Library.

Our research considers how physical space shapes the way that patrons think about and use the Spring Garden Road Memorial Public Library. Informed by sociological theories of public space, our research question is:

\section{How does the social production of the Spring Garden Road Memorial Public Library contribute to its users' social construction of the space?}

In order to address this question, we use documentary research in combination with on-site observation of the physical space and interviews with library patrons. In this way, we gain insight into how users' behavior at the SGL relates to their opinions of the current building, and the future Halifax Central Library. 


\section{AN EVOLVING ROLE}

The SGL opened in November 1951 as a memorial to the Halifax casualties of World War I and World War II (Halifax Central Library 2012a). In the decision to build a war memorial, Halifax residents believed the library was most suitable not only due to the need for a library, but also because it would be a "living memorial," promoting the same tenets which Haligonians were defending in the wars: "freedom of speech and freedom of study" (para. 9). The social and political contexts of the time were thus built into the very fabric of the library building, including the many memorial symbols such as the two books of remembrance and Silver Cross replica, and confer a special historical meaning to the library for the Halifax community (Halifax Central Library 2012a).

However, as a result of the amalgamation of the Halifax Metropolitan area, the growing service area and population needed a central library to fulfill the expanding and changing needs of the citizens (Halifax Central Library 1996). Although the SGL was the hub of the Halifax City Regional Library system, surveys and reviews of the physical structure and library users' experiences and perceptions of the library found the building inadequate to serve as the central library (Halifax Central Library 1996). A building expansion in 1973-1974 failed to meet space demands by 1987. By the 1990s it was clear that high costs made renovation of the existing structure unfeasible. (Halifax Central Library 1996, 2004).

Recent opinions of the Spring Garden Road Memorial Public Library reflect the tension between the library's historical roots and physical design and modern-day expectations and needs. Halifax Central Library surveys (in 1996, 2004, and 2008) and focus groups with local residents found sentiments such as appreciation for the setting and atmosphere of the building, its staff and programs, but dislike for the building's confusing layout and cramped space, lack of accessibility, and limited seating and quiet space. The report "Central Library Project: Study for the Halifax Regional Library” states, “The building defies almost every aspect of current standards and building codes regulating this type of facility" (Diamond, Schmitt and Company 1997, 13). Therefore, the material space of the library, together with its conceived intent, contributes to user experience and perception, which in turn affect the desirability of the new central library.

Overall, the history of the SGL reflects broader changes to the city of Halifax including: the role of local citizens in world wars; population growth; and different approaches to municipal governance. All of these factors contribute to contemporary expectations of the library that have evolved out of but are different from the ideas that shaped the original construction of the library. A range of policy documents demonstrate that municipal authorities in Halifax recognize that public libraries reflect social values and play a role in urban vitality. While the existing SGL is an expression of Halifax's past, the future Halifax Central Library is part of a vision for the revitalization of downtown Halifax and the provision of services to people across the HRM (Halifax Public Libraries 2012b).

\section{THE PLACE OF LIBRARIES}

As a result of its history, the SGL thus is a special physical and symbolic entity in Halifax's landscape. Our research builds on the unique position of the library in the city and focuses on the relationship between the social production and social construction of space. According to Goheen $(1998,479)$, the SGL's status as a public space means that the library is a dynamic resource venue where interaction occurs freely between citizens, institutions, and the surrounding physical area. In addition, the users of a public space define and shape the space, which in turn will reflect the attitudes and cultural meanings of that society. The physical space of the library refers to the interaction between the various elements of a built environment, as well as the environment's relationship with the surrounding context of a larger region (485). Low's (1996, 861) concept of the social production of space describes the "social, economic, ideological, and technical" components that together create a physical space. Such components can include planning and design, the intended purpose of the space, and construction materials. The social construction of space, on the other hand, is the process of attaching meaning and symbolic value to a space through personal experiences, memories, images, and ideas of the space (861-862). The social production of space is relevant to the social construction of space in determining the context from which a space develops, and its potential influence on current experiences of the space. Low coined the concepts of the social production and social construction of space to examine the ways in which the histories and designs of two different public plazas in San José, Costa Rica, influence the social experiences and uses of the spaces. Conflict between plaza users, the general public, and businesspeople arise over the social claim to the spaces by different interest groups. Diverging beliefs of what the plazas represent in Costa Rican culture, what they are intended for, how they should 
be used, and how they should be presented to the public create mixed perceptions, feelings, and experiences of the plazas (Low 1996). Therefore, the public does not encounter a space in isolation, but rather as a culmination of several interconnected factors.

Low's (1996) discussion of the social production and construction of space parallels the distinction between design and use found in the research of public libraries in North America (Leckie and Hopkins 2002; Mattern 2007). Mattern's 2007 book The New Downtown Library analyses recent constructions of public libraries in American cities within the context of urban revitalization initiatives and explores the relationship between a library's architecture and its objectives. Mattern finds that social dynamics are just as important as material considerations in determining how public libraries are built and used. Similarly, in their article, "The Public Place of Central Libraries: Findings from Toronto and Vancouver," Leckie and Hopkins (2002) acknowledge that both physical space and social interactions define public libraries. They outline the factors that contribute to a successful public space and consider the function of libraries in contemporary society. Leckie and Hopkins analyze the intended purpose of public libraries in relation to the range of spontaneous, individual activities that their research uncovered at the central libraries of Toronto and Vancouver. As a result, they also discuss the broader social role of public institutions. In particular, Leckie and Hopkins $(2002,327)$ state, "The physical library itself is a material expression of shared meaning and values of public life." As a living memorial, the SGL is a prime example of such a marriage between physical design and public values, and can be better understood through Low's conceptual framework of social production and construction of space. Thus, our research examines how the physical space of the library, including its construction and physical arrangement, in combination with the historical context and intended purpose of the library, affect the way users engage with, experience, think about, and remember the Spring Garden library.

\section{RESEARCH DESIGN: STALIING THE STACKS}

We combined two distinct methods to capture how users of the SGL experience the physical space. First, we conducted unobtrusive observations of the main floor of the library, which contains the circulation services and the general adult collection. Second, we conducted short personal interviews of library users as they exited the space. The articles of May (2011) and Leckie and Hopkins (2002) informed our research method. May (2011, 355) details the importance of researching "the library in the life of the user" versus "the user in the life of the library." In addition, Leckie and Hopkins $(2002,326)$ introduce various observational and interview techniques to capture the "big picture" of the space.

Prior to conducting our fieldwork on this topic, we drew some preliminary hypotheses relating to the users' social construction of space. Since the SGL itself is inadequate to serve the Halifax population and their needs, we believed that the social production of the library detracts from users' perceptions of the space. We thought such factors as cramped space, insufficient lighting, and poor physical accessibility might combine to create negative associations and experiences of the space. However, pleasant memories of long-term library users familiar with the institution's history might create a positive social construction of the space despite the building's physical limitations.

In total, we visited the library eleven times to gather data. We conducted the first visit as a group to observe elements of the physical space, including temperature, light, odor, and noise level. Additionally, we made note of the approximate dimensions of the space and how the arrangement of furniture contributed to the atmosphere of the library. We used this data to create floor plan maps for noting location-based details and movement patterns. We divided the main floor of the library into three separate areas: the Main Room, the Reading Room and the Stacks (Figure 1).

Following the preliminary visit, each researcher visited the library three or four times so that, in total, our team visited the library ten times to make unobtrusive observations of the people and activity within the library. Each research visit lasted fortyfive minutes to an hour. Our observations took into account both qualitative and quantitative dimensions of user activity, noting where users gathered, how long they stayed, and approximately how many users were in each area at one time. In addition, we noted whether visitors conducted their activities in groups or individually, and observed visitors' movement patterns throughout the library.

During our visits, we interviewed a total of thirty-one users as they were leaving the main floor of the library. In order to minimize disruption within the library, we stopped users in the foyer outside the quiet inner space. Leckie and Hopkins (2002) provide a model of interview questions from which we developed our own version. The interview questions (see Appendix) aimed to capture the intent of library users, their interactions and activities within the space, and their overall feelings about the library's layout and purpose within the community. Additionally, we included questions about memories associated with the space in order to 


\section{Spring Garden Road Memorial Public Library: Floor Plan}

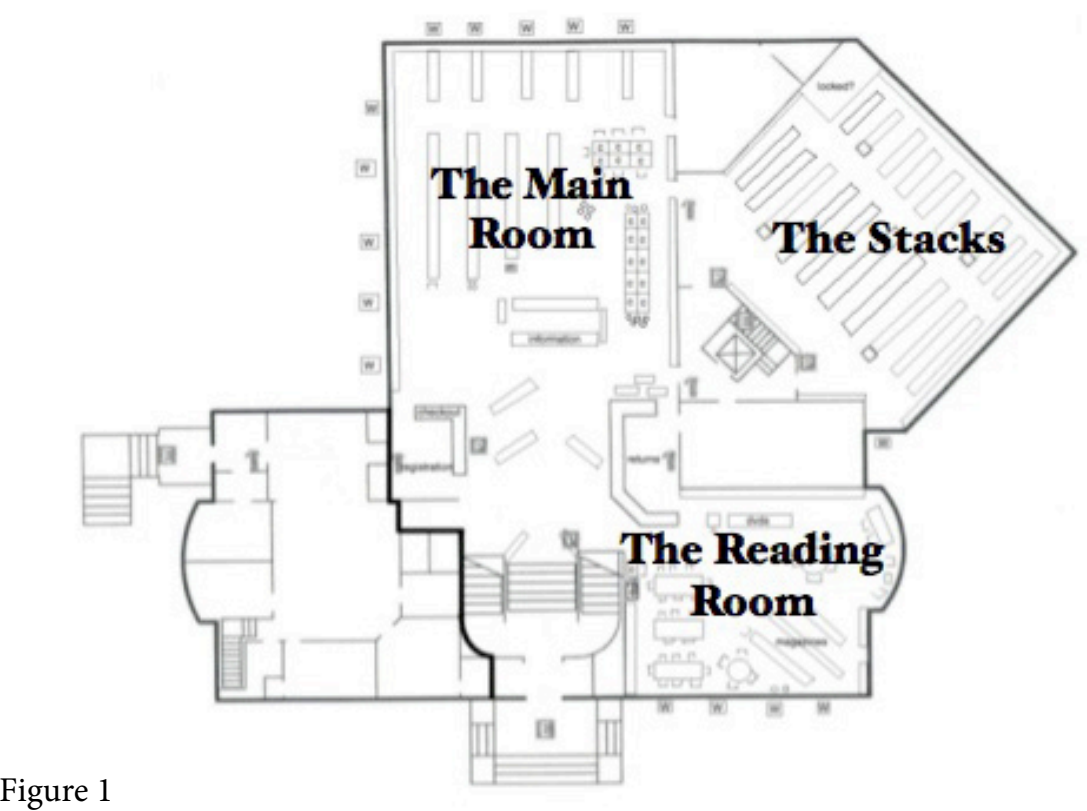

examine any long-term negative or positive perceptions. Finally, we asked what users would change about the library to improve it for the community. To analyze our data, we entered the responses from our interviews into an interactive online spreadsheet, which allowed us to compare and contrast the answers to each question and compile data from each of our individual visits to the library. We classified responses as positive, negative, or neutral based on the interviewees' verbal and non-verbal cues. We noted recurring themes and responses that deviated from the norm. We summarized our individual observations of the space, highlighting what developing trends and anomalies we found, and then compared summaries to draw out broader patterns, themes, and incongruities.

Specifically, we compared the activity in each of the three areas by day of the week and time of day. We focused on patterns of use and movement throughout the space. We assumed a correlation between preference and the number of visitors engaged in an activity within a space at one time. For example, fewer users of a certain space might indicate that the area is less desirable. We also considered how aspects of the physical space such as light and temperature could influence visitors' choices.

When considering the ethical implications of our research, we addressed two main issues before entering the field. First, we sought permission from the Branch Manager of the SGL. Although the library is a public institution, we felt it was still important to request permission so as to minimize intrusion and potential disruption to the library setting. Additionally, we established a pattern of identifying ourselves with the librarians at the Information Desk at the start of each observation session. In this way, our slightly irregular behavior would be expected. Second, we considered the ethical implications related to the interview process, including informed consent and confidentiality of information. Since our interviews were both anonymous (no names were collected) and about five minutes long, we decided that written consent forms were unnecessary. Instead, we read a script at the beginning of each interview to ensure that the respondent understood the aims and conditions of the research and how his or her answers would be used (see Appendix).

\section{"ALLTHE NOOKS AND CRANNIES": HOW SPACE SHAPES USE}

Furniture and architectural features shaped users' activities in the Main Room. The entrance area of the library, which consists of an open space between the doorway and the three customer service desks, facilitated brief, focused visits (Figure 2). Waisthigh bookshelves funnelled arriving patrons in the direction of the Information Desk but attracted the attention of several visitors on their way out. This suggests that although many people came to the library with specific tasks in mind, towards the end of their visit they were more inclined to browse and explore other aspects of the space and collection. Many users entered the Main Room, went straight to the Check Out, Return or Information Desks and left in less than five minutes. As Interviewee \#18 explained, "I don't really hang out here - just get books and go." This attitude may be a response to the limited seating and congestion of certain areas of the library. For example, the shelf displaying special interest books was located next to the computer stations and was often surrounded by a crowd of both browsers and computer users. In addition, several interviewees noted that the lack of seating throughout the entire library discouraged them from "settl[ing] down for a while" 
(Interviewee \#23) and enjoying a quiet, comfortable read, which likely accounts for the large number of quick door-to-desk-todoor visits. Despite the limitations of the arrangement of furniture, architectural features contributed to a positive atmosphere. The high ceiling and ample natural and artificial lighting of the Main Room provided a sense of space that compensated for and relieved the tension of a density of people and objects.

The arrangement of the two computer stations in the Main Room influenced how patrons used these electronic resources. One computer station, the "standing computers," is a long table of elbow-height bearing ten computers that require patrons to stand while they browse, as there are no chairs provided (Figure 3 ). The other station, the "sitting computers," is a set of six computers on desks with chairs. Despite the close quarters, walled partitions separate each of the computers and provide a sense of privacy in the midst of a public space (Figure 4).

Patrons used the standing computers on average for no longer than ten minutes; most referred to the library catalog, and then proceeded to other areas of the library. In contrast, patron use of the sitting computers was constant and most often neared the capacity of the station at any given time. Although the library

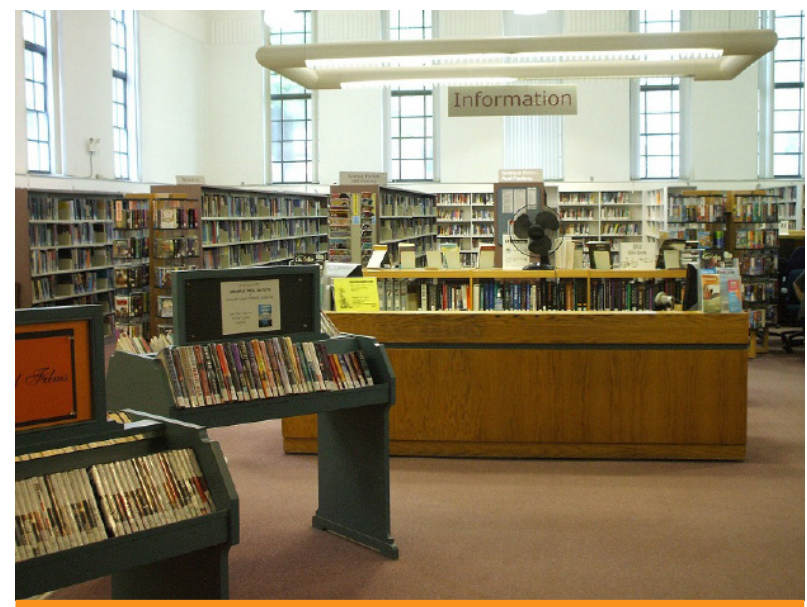

Figure 2

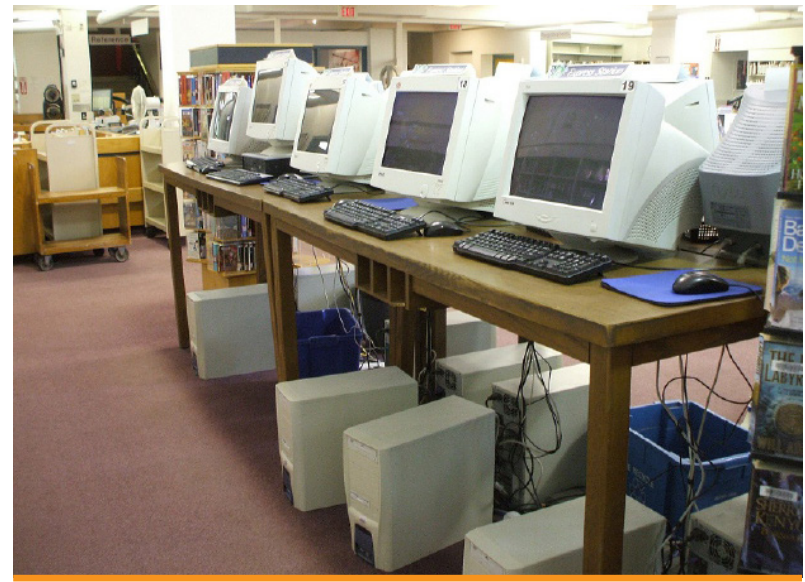

Figure 3

designates a thirty-minute usage limit on the sitting computers, patrons often stayed for more than forty-five minutes, taking advantage of the relative privacy of these partitioned stations and using the computers for personal purposes. For example, describing his use of the sitting computers, Interviewee \#25 exclaimed, "I just paid my taxes in 8 minutes!" Conversely, dividers did not shelter the standing computers. The lack of privacy combined with the height of the station made the computers awkward and uncomfortable to use, especially for senior patrons. Overall, the different arrangements of the two groups of computers reflect each station's intended use: quick, library related activities, and prolonged personal activities.

Observations of the Reading Room demonstrated that the space of the library accommodated both conventional activities and spontaneous individual behavior. Initially, we had assumed that the DVD collection would be less important than the print resources in the library. However, the DVD wall was one of the most highly trafficked areas in the library, often crowded with visitors perusing the tight space (Figure 5). Approximately one to four users browsed the DVD section at any one time, which is significant considering the space's small size. The continuous interest and activity around the DVDs showed that, as Interview \#21 expressed, users valued the library for "more than just books," and the area's popularity had been underestimated in the SGL's design, as reflected in the limited amount of shelf space allocated for DVDs. 


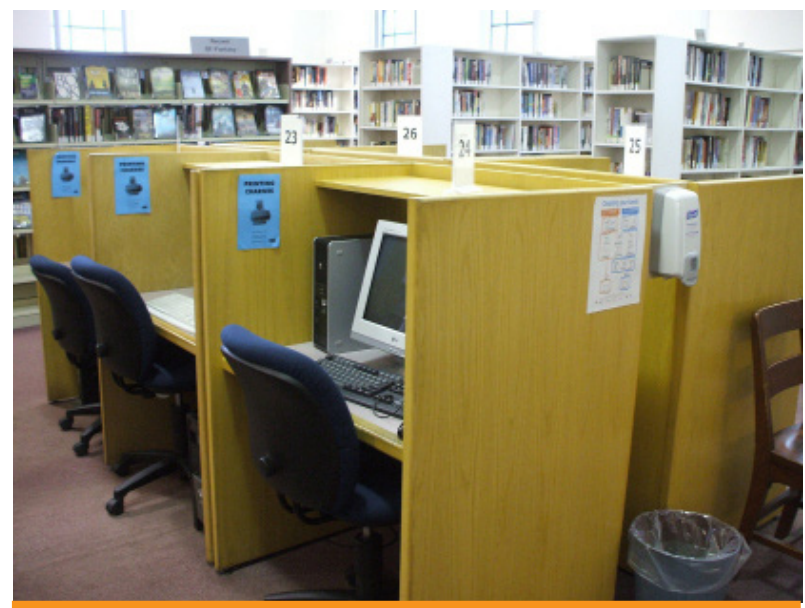

Figure 4

The three rectangular tables and two comfy chairs in the Reading Room provided seating for a range of activities, which was absent from other areas on the main floor. We assumed that these tables are intended for people to sit and read books, magazines, or quietly work. We found that patrons used the tables for these expected activities as well as other purposes. On a few occasions, groups of youth literally surrounded the rectangular tables and engaged in audible conversation rather than quiet activity. In other cases, browsers of the DVDs used the tables as a surface to display their materials and free up their hands for further browsing. Some people sat at the chairs without using the tables and engaged in quiet cell phone calls and text messaging. One weekend morning, an individual even ate a take-out breakfast sandwich at a table in the Reading Room. However, for the most part, patrons used the tables for their intended purpose: reading and working. Finally, in addition to the seating provided at the tables, several interviewees identified the comfy chairs in the Reading Room as their favorite place in the library, explaining that these chairs had "more padding" and were good for "people watching" (Interviewee \#23).

Both the activities and the physical features associated with the non-fiction Stacks discouraged visitors from lingering in this area. In contrast to the natural light, high ceiling and carpeted floor of the Main Room, the Stacks had fluorescent tube lights, a lower ceiling, and tiled floor. Additionally, the area sported one solitary window, tight spacing between shelves, and a colder temperature

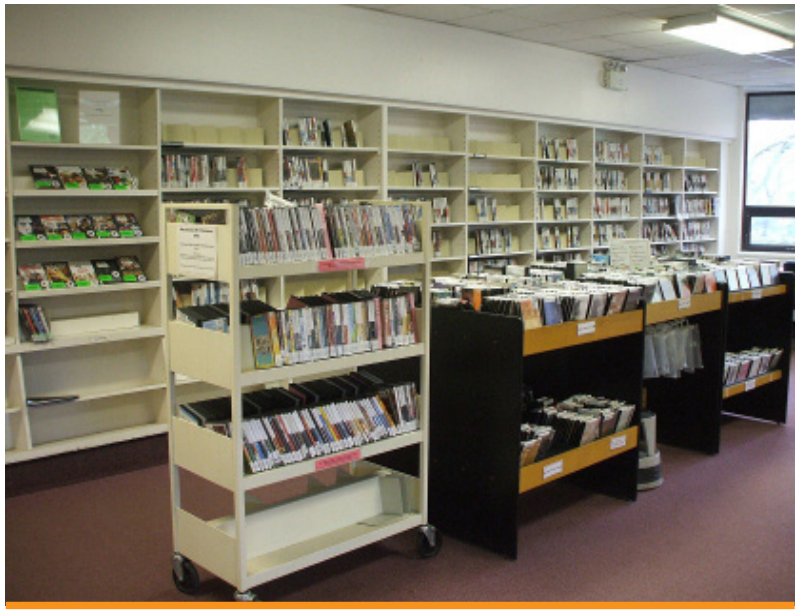

Figure 5

accompanied with the musty smell of old books (Figure 7).According to Interviewee \#23, the atmosphere was "dingy," similar to "a records hall in the basement of a high school." All of these elements made the Stacks the least welcoming section on the library's main floor. Consequently, visitors spent less than five minutes in the Stacks on average and rarely browsed the shelves, instead searching for particular items after consulting the online catalog or a librarian. Yet, users appeared to have difficulty locating materials, as Interviewee \#10 admitted, "I get lost," and patrons often left empty-handed after a few minutes of searching (Figure 8).

\section{RETHINKING A FAMILIAR PLACE}

Our interviews both confirmed elements of our observations and highlighted the complex ways that people use and think about the library. First, interviewees reinforced the importance of electronic resources, particularly computer access and the DVD collection. As well as noting the importance of these services, respondents also suggested possibilities for expansion. Interviewee \#1 said that he would change "the computer system, put them all against the wall, have it open in different areas." Another interviewee (\#29) suggested that the library could have a program to lend laptops to library users. A third interviewee (\#21) expressed interest in extending the lending period for DVDs. Second, although our observations of the Stacks identified infrequent 


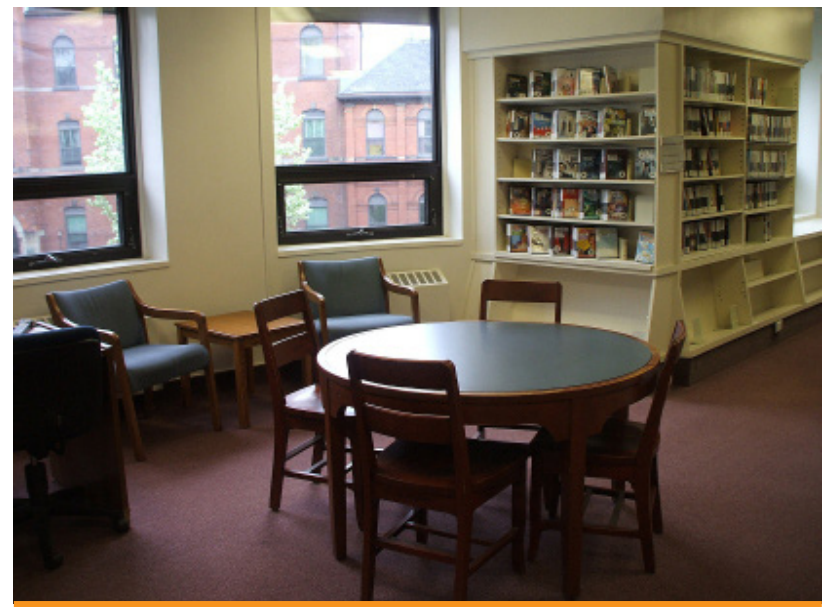

Figure 6

use and an unwelcoming atmosphere, not a single interviewee identified this area as his or her least favorite place. Third, just as we observed both advantages and disadvantages of the natural and artificial lighting, users also gave lighting mixed reviews. Interviewee \#4 said, "I like the way the light comes in there, and along there," gesturing to the windows itn the Reading Room and in the Main Room. Interviewee \#30, however, listed "lighting" as the aspect of the library that he would like to change.

Comparing the responses to three questions gives insight into the users' perceptions of the library. Specifically, the questions investigated interviewees' favorite and least favorite places, and any changes they would make to the library. Interviewees most commonly reported the Reading Room as their favorite place, highlighting the comfy chairs, the useful workspace provided by the tables, the DVD and magazine collections, and the natural light from windows. A significant number of respondents could not identify a favorite place. However, interviewees also had difficulty settling on a least favorite place; eighteen out of thirty-one could not name a least favorite place. The absence of both favorite places and least favorite places could be a result of unfamiliarity with the physical layout or general impartiality towards the library as a space. On the other hand, patrons familiar with the library may be accustomed to experiencing it as a whole, making it difficult to distinguish specific sections of the library as favorable or unfavorable. Some respondents, however, listed the washrooms and the basement as their least favorite place.
The question "If you could change one thing about this library, what would it be?" yielded diverse responses. Respondents identified changes to both the structure and the services of the library. Some interviewees did not specify what kind of renovations they desired. However, others mentioned layout changes that would create "more space for sitting and reading comfortably" (Interviewee \#11). Interviewees listed the overcrowding, limited collection, and inconvenient hours of the library as other areas of improvement. Interviewee \#4 was dissatisfied that the library "has to close down in the summer when it gets too hot." Finally, four respondents said that they would not change anything about the library. The contrast between interviewees' ideas of how to improve the library and their hesitance to share a least favorite place indicates that although users may not have strong feelings about any one place in the library, they still recognize general flaws in the library's design and services.

When asked to describe the library in one word, the majority of interviewees responded with positive descriptors. The positive answers fall into five thematic categories: utility of the library, with

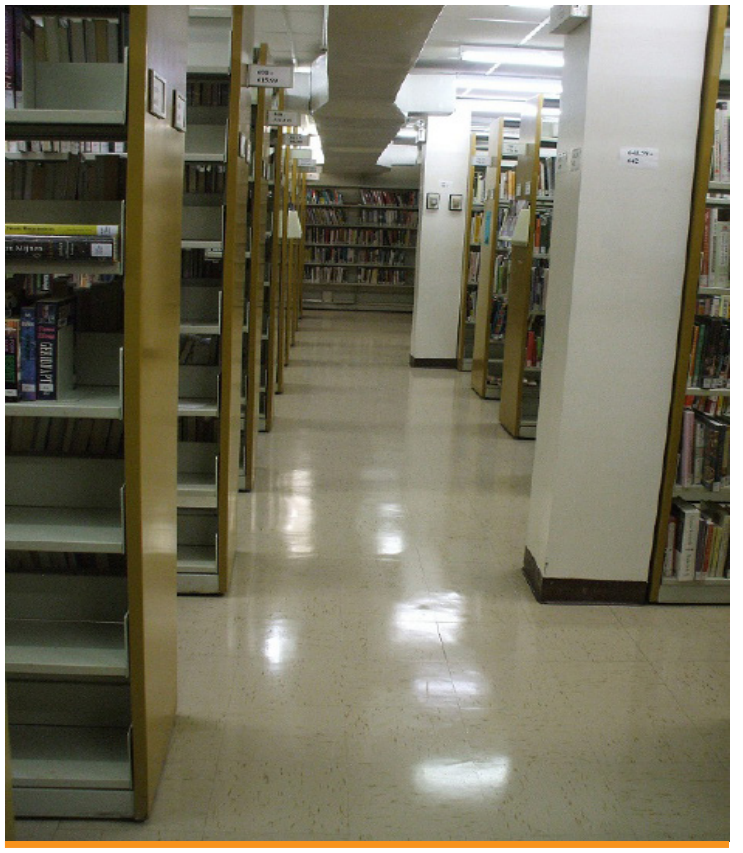

Figure 7 


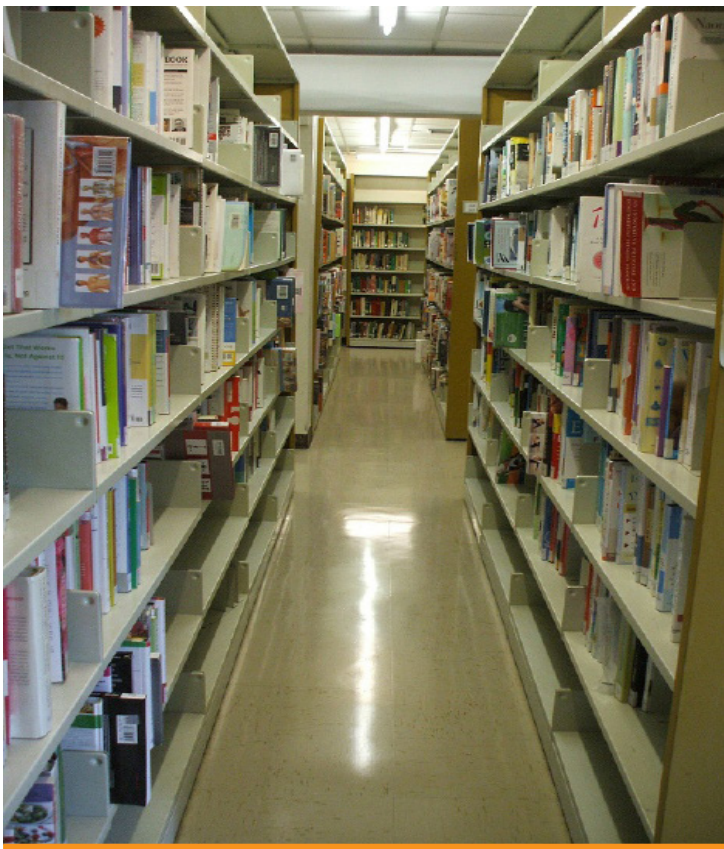

Figure 8

words such as "necessity" and "convenient"; the library's warm atmosphere, such as "comforting" and "welcoming"; historical relevance of the library, such as "has a story" and "historic"; the library as gathering space, such as "node" and "community"; and miscellaneous positive descriptions, such as "magnificent" and "flows." Three interviewees provided negative responses, two of which hold the library as "outdated," and one as "small." Three other responses are neutral, two relating to libraries in general as "books" and "learned," and one relating to time and space as "present." The interviewees' responses indicate that the interviewees have overall positive experiences and ideas of the library, and appreciate first and foremost the usefulness of the library and the services it offers. Contrary to our observations of the physical space of the library, which found the physical condition and layout of the building lacking, interviewees feel the library has a pleasant environment, with several noting fondness and respect for the library's historical background. However, the positive responses focus on subjective experiences and perceptions of the space, rather than the actual physical state of the library. Considering that several of the same interviewees desired changes to the physical space, the interviewees' emotional connection to the SGL may override the negative aspects of the building and produce a general satisfaction with the library.

\section{NEW LIBRARY, OLD OPINIONS}

When asked about the Halifax Central Library, many patrons hesitated to embrace the new facility. The contemporary aesthetics of the Halifax Central Library challenged many patrons' loyalty to the older architectural style of the SGL. Interviewee \#1 explained that the Halifax Central Library will "not [have] the class of the old building, this has history to it." Similarly, Interviewee \#3 said, "I'm kinda scared for the new library. I like the old building." While Interviewee \#10 described the design of the Halifax Central Library as "too glassy," Interviewee \#7 went so far as to say that it "looks like an aquarium, all you need is fish." In some cases, misgivings about style were also linked to finances and, according to Interviewee \#13, "it seems like the architect got carried away." Concerns about the utility of the new library exacerbated patrons' anxiety about the project's cost. For example, Interviewee \#17 worried that the new library "could be a waste of money," because the existing building "seems sufficient." Committed to preserving the integrity of the current library but also improving its services, Interviewee \#26 expressed this tension, saying: "I have mixed feelings about the new library. I understand the need to expand the library to give more access to the general public, but I would prefer if they instead renovated the existing building."

Nevertheless, users recognized the positive potential of the Halifax Central Library. Many interviewees believed that a new facility would allow more people to take advantage of library services. Interviewee \#12 thought that the Halifax Central Library will be "better for current patrons and will attract new patrons." Interviewee \#22 described it as "a bigger and better space that is more inviting for people," which may also address the physical accessibility issues of the current library (Interviewee \#24). Additionally, users were optimistic that the Halifax Central Library would offer expanded electronic resources and increased operating hours (Interviewee \# 7; Interviewee \#8). Interviewee \#27 was confident that "It'll be very nice, more modern, more computers, more services," and even suggested that the new library could offer a laptop checkout program. In this way, patrons looked forward to certain elements of the new library even as they remained connected to the history of the SGL. 


\section{FINDINGS FROIM SIIMILAR STUDIES}

Just as we heard many positive comments about both obvious and unexpected aspects of the SGL, other studies find that, by accommodating both intended and unintended activities, public libraries serve a beneficial role for many people. Leckie and Hopkins $(2002,353)$ conclude that libraries serve the diverse needs of two groups of users: the first group sees the library "as an extension of their living room" and visits on a regular basis, while the second group prioritizes "quick and convenient access to a large collection" and visits less frequently. In this way, our observations were consistent with the findings of other researchers. Patrons who lingered in the comfy chairs, gathered around the large tables with friends, or ate breakfast in the Reading Room treated the SGL as a comfortable, familiar space. Indeed, the SGL's rooted history in Halifax fosters positive emotional attachments not only to the building, but also to what the institution represents. Conversely, for patrons who visited the SGL on occasion for specific purposes, the library held less emotional value. Several of these patrons cited the physical limitations of the building as reason for their brief visits or weaker attachment to the library. Following in Low's (1996) framework of social production and social construction, we see how the historical and social contexts, as well as the physical space of the SGL, created diverging attitudes toward and feelings about the library.

\section{RESEARCH LIMITATIONS}

Although we aimed to investigate users' perceptions of the library, short interviews provided limited insight into whether or not users had an emotional connection with the space. Despite the fact that most respondents had been coming to the library for a long time or were frequent users, few people shared memories of the space. People may have been uncomfortable sharing personal stories in the informal context of a short interview, or they may have found it difficult to think of a specific story connected to this very familiar space. Longer interviews, in which interviewees have an opportunity to elaborate on a variety of topics, might encourage greater discussion of individuals' feelings towards the library.

Another limitation of our research is the small sample size, and the lack of sample diversity. The thirty-one patrons we interviewed cannot be representative of the large body of patrons who use the SGL. However, their answers point to the possible range of responses, feelings, and experiences relating to the library. We observed whoever made use of the library's main floor during their visit without selecting for a certain gender, age, ethnicity, or socioeconomic status. Similarly, we interviewed anyone who exited the main floor of the library during our interview period. As a result, our observations and interviews reflect the prevailing demographic of library users. White males aged thirty-one to sixty composed a significant portion of this group. Although we made an effort to speak with different patrons, the gender imbalance among our interviewees corresponds to trends we observed among library users. A larger sample size would allow us to expand the scope of our research and consider how age and gender, among other factors, shape how people use and perceive the SGL.

In addition, the time of year we completed our research, late winter, may have affected who used the library and when, and for what activities. For instance, the cold weather or snow may have deterred or made it difficult for some users to visit the library. A six-week-long Halifax public transit strike also occurred during our research, and may likewise have affected library usage. A year-round study would provide the most representative and varied results, such as revealing how the library's high temperature in the summer dissuades some from going to the library, as one interviewee reported.

Another limitation of our study was that we did not interview any library staff. As people who spend a great deal of time at the library and who are trained in library science and information management, library staff are excellent sources of information. Over the course of their regular activities, staff may have developed insights into the habits of people at the library and the strengths and weakness of the space. Also, staff may contribute to our understanding of the extent to which user behavior is controlled by the library's design. Specifically, they may be able to explain the intentions behind the layout of furniture, books, and other materials.

\section{"THIS HAS HISTORY": A MEMORIAL LIBRARY}

We found that the social production of space informs the social construction of space for users of the Spring Garden Road Memorial Public Library. Municipal policy documents explained 
the library's history, its role within the city of Halifax, and its current limitations. In addition, direct observation highlighted specific physical features of the building, such as how the arrangement of library material and furniture influenced patrons' use of the space. Observations of and interviews with users offered insight into the social construction of space. In general, respondents' comments about the library did not reflect the physical limitations that we observed during our fieldwork and read about in policy documents. Users' positive feelings about the historic building seemed to be more powerful than their complaints about inadequate elements of the space. Many interviewees described the library's age in positive terms, noting, for example: "the class of the old building" (Interviewee \#1) and "the historic feel" (Interviewee \#27). In particular, Interviewee \#25 explained, "I would make the inside of the library look more like the outside. The outside is epic and historic...much more than the inside...It doesn't seem to match." Overall, users' responses reveal an emotional and aesthetic rather than pragmatic attachment to the library, which constructs this building as a historic whole that is greater than the sum of its outdated parts. In the case of the SGL, the building's original intent is more important than its current condition in shaping the way people view the space. Therefore, users' ideas about the Spring Garden Road Memorial Public Library contribute to the meaning of this institution in the past and present of Halifax.

\footnotetext{
Appendix:

Interview Questions and Verbal Confidentiality Agreement

Hello, my name is I am a student at Dalhousie University doing a sociology study on the library. Would you be interested in answering some questions? It shouldn't take more than 5 minutes.

Just to let you know a little bit more about the project -- We are studying how people use and think about the library. This information will be used for a written paper as well as a presentation to the class at the end of the year. Your identity and responses will be kept confidential and will remain anonymous in the report.

What are you doing here today?

Did you talk to the library staff today?

Did you talk to any other users while here? Strangers or not?

Did you use the electronic resources today?

Do you have a favorite place in the library? Why?

Do you have a least favorite place? Why?

How long have you been coming to this library?

How often do you come to this library?

Do you have any memories associated with this library?

If you could change one thing about this library, what would it be?

Are you aware of the construction of the new library? How do you feel about it?

How would you describe this library in one word?

May (2011) suggests visitor tracking as a method of observation, whereby the observer inconspicuously follows users from entry to exit to track movement, activity and progression of use. However, we determined this method was not suitable for our research as the SGL is not large enough to allow inconspicuous tracking without disrupting user activities and privacy.
} 


\section{WORKS CITED}

Diamond, A.J., and Donald Schmitt and Company. 1997. “Central Library Project: Study for the Halifax Regional Library." http://halifaxcentrallibrary.ca/assets/pdfs/

Goheen, Peter G. 1998. "Public Space and the Geography of the Modern City." Progress in Human Geography 22:479-496.

Gottdiener, Mark. 1993. "A Marx for Our Time: Henri Lefebvre and The Production of Space." Sociological Theory 11:129-134.

Greenhalgh, Liz, and Ken Worpole. 1995. Libraries in a World of Cultural Change. London: University College London Press.

Halifax Central Library. 1996. “Towards a New Central Library: Present Use and Limitations of the Spring Garden Road Library and Projected Needs for a New Central Facility." http:// www.halifaxcentrallibrary.ca/reports-documents.html

—. 2004. “Needs Assessment and Master Facilities Plan." http://halifaxcentrallibrary.ca/reportsdocuments.html

—. 2008. "Appendix B: Summary of Survey Results from Public Meeting \#1." http://www. halifaxcentrallibrary.ca/public-consultations/2008-public-consultation-process/surveys.html.

—. 2012a. "Background and History."http://www.halifaxcentrallibrary.ca/building-design/sgr-warmemorial/background-history.html

—. 2012b. "The Vision." http://www.halifaxcentrallibrary.ca/the-vision/

Halifax Public Libraries. 2011. "Halifax Public Libraries Performance and Trends 2010-11." http:// www.halifaxpubliclibraries.ca/about/documents/plans-reports.html.

Leckie, Gloria J., and Jeffrey Hopkins. 2002. “The Public Place of Central Libraries: Findings from Toronto and Vancouver." The Library Quarterly 72:326-372.

Low, Setha M. 1996. “Spatializing Culture: The Social Production and Social Construction of Public Space in Costa Rica." American Ethnologist 23:861-879.

Mattern, Shannon. 2007. The New Downtown Library. Minneapolis: University of Minnesota Press.

This work is licensed under a Creative Commons AttributionNonCommercialNoDerivs 3.0 Unported License.
May, Francine. 2011. "Methods for Studying the Use of Public Spaces in Libraries." The Canadian Journal of Information and Library Science 35:354-366. 